\title{
Therapeutic options for patients bleeding with peptic ulcers
}

\author{
ABR THOMSON MD PhD FRCPC FACP FRS FACC
}

ABR THOMSON. Therapeutic options for patients bleeding with peptic ulcers. Can J Gastroenterol 1994;8(4):269-274. It is likely that the best outcome for the patient with an acute upper gastrointestinal bleed (GIB) includes early diagnosis: for a bleeding lesion with a high risk of rebleeding, in an older patient with systolic hypotension or in a person with multiple medical problems. Early therapeutic endoscopy with meticulous control of intragastric $\mathrm{pH}$ will likely achieve the best outcome. The ideal $\mathrm{pH}$ criterion to stop bleeding or to prevent recurrence is unknown. An algorithm is presented to guide the clinical management of patients with GIB, and to focus on important questions for future therapeutic studies.

Key Words: Acute hemorrhagic gastritis, Duodenal ulcers, Gastric ulcers, Intragastric pH, Therapeutic endoscopy, Upper gastrointestinal bleeding

\section{Options thérapeutiques pour les patients porteurs d'ulcères gastroduodénaux qui saignent}

RÉSUMÉ : Le pronostic a de meilleures chances d'être favorable chez les patients qui souffrent d'une hémorragie gastro-intestinale supérieure aiguë si le diagnostic est fait précocement : chez les sujets âgés qui ont une lésion hémorragique accompagnée d'un risque élevé de nouveaux saignements qui ont une hypotension systolique ou qui présentent de nombreux problèmes de santé. L'endoscopie thérapeutique précoce, accompagnée d'un contrôle méticuleux du pH gastrique, est le plus susceptible d'amener un meilleur pronostic. Le critère quant au $\mathrm{pH}$ idéal pour cesser l'hémorragie ou prévenir sa récidive reste à définir. Un algorithme est présenté afin de guider le traitement clinique des patients qui manifestent une hémorragie gastro-intestinale haute et d'insister sur les questions importantes relatives aux études thérapeutiques à venir.

Nutrition and Metabolism Research Group, Division of Gastroenterology, Department of Medicine, University of Alberta, Edmonton, Alberta

Correspondence and reprints: Dr ABR Thomson, 519 Robert Newton Research Building, University of Alberta, Edmonton, Alberta T6G 2C2. Telephone (403) 492-6490, Fax (403) 492.7964

Received for publication November 2, 1993. Accepted February 14, 1994
PPER GASTROINTESTINAL TRACT
bleed (GIB) is a common medical emergency which constitutes approximately $15 \%$ of the workload of major Canadian teaching universities (1). About $30 \%$ of these patients rebleed, $20 \%$ require emergency surgery and $5 \%$ die $(2,3)$. Surgery is usually indicated for severe, persistent or recurrent bleeding. Any treatment that might delay surgery to optimize the opportunity to stabilize patients, or prevent its need in the first place, would be useful. Any medical therapy that could reduce the risk of rebleeding or death would be of even greater value.

The therapeutic options for patients with bleeding peptic ulcers include surgery, therapeutic endoscopy (Table 1) and drugs. After appropriate resuscitation, current medical therapy includes mechanical compression of the bleeding vessel using the various forms of therapeutic endoscopy. The choice of drugs that might improve the clinical outcome of patients with GIB includes antifibrinolytic therapy, reduction in splanchnic pressure with somatostatin (or a long acting analogue such as octreotide) or acid-lowering measures using $\mathrm{H}_{2}$ receptor antagonists or proton pump inhibitors. 


\section{TABLE 1 \\ Endoscopic therapy of bleeding ulcer}

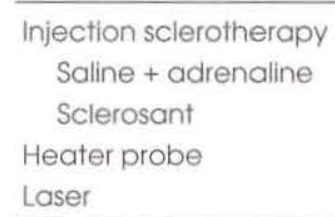

Sclerosant

Heater probe

Laser

\section{THERAPEUTIC ENDOSCOPY}

Diagnostic endoscopy has assumed an important role in the management of patients with GIB because of its accuracy in establishing a diagnosis, in determining which patient is likely to continue bleeding and in identifying which patient may benefit from a therapeutic intervention (4). From the reported results of controlled clinical trials $(5,6)$, participants of the 1989 United States National Institute of Health Consensus Conference (7) recommended that therapeutic endoscopy be the hemostatic procedure of first choice for patients with ulcers at risk of rebleeding. Numerous forms of endoscopy therapy are available (Table 1). Sacks and colleagues (6) performed a meta-analysis that demonstrated that therapeutic endoscopy reduces the need for emergency surgery by nearly two-thirds, and reduces the mortality rate of patients with GIB by nearly onethird. Injection therapy is equal to that of thermal methods such as YAG laser (8) or multipolar electrocoagulation (9), while equal or inferior results are achieved with heat probes $(10,11)$.

Let us consider an important study that strongly emphasizes the importance of therapeutic endoscopy in GIB. In a series of 1880 patients admitted consecutively to a single hospital in Barcelona with a bleeding peptic ulcer, 341 had a high risk of further hemorrhage as assessed by the presence of active arterial bleeding or a nonbleeding visible vessel (12). These were older patients with a mean age of $64.9 \pm 15$ years. The location of the ulcers was: $58 \%$ duodenal, $32.3 \%$ gastric, $5 \%$ stomal and $4.7 \%$ pyloric. A nonbleeding visible vessel was seen in $65.1 \%$, oozing in $31.4 \%$ and spurting in $3.5 \%$. Adrenaline was injected ( 1 per 10,000 , aliquots of 1.0 to $2.0 \mathrm{~mL}$ first around

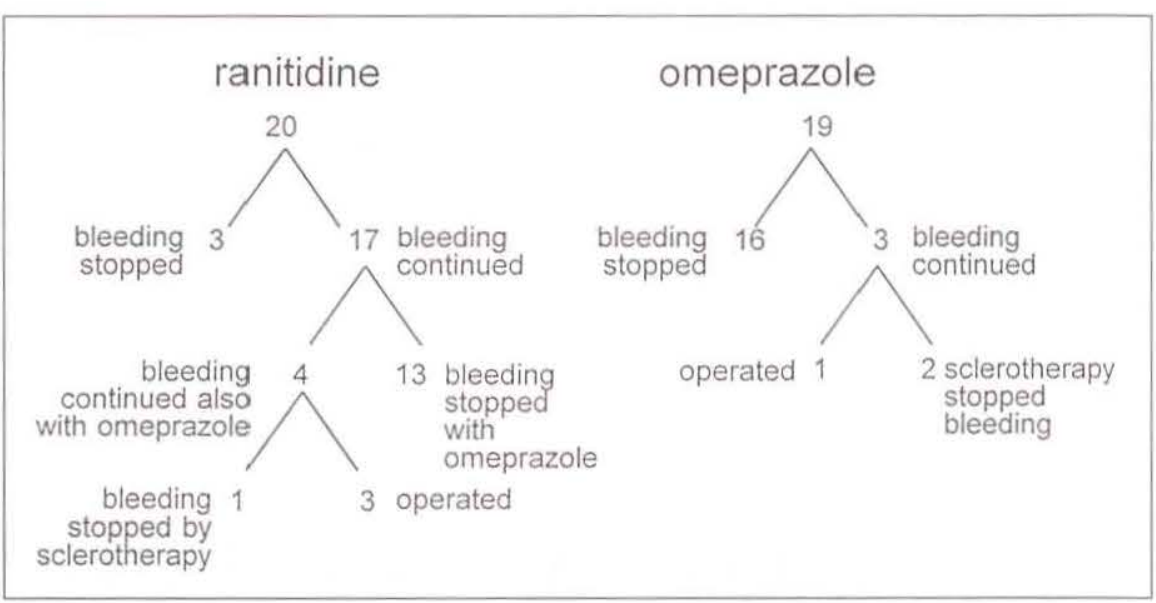

Figure 1) Omeprazole/ranitidine in patients with bleeding peptic ulcers. Reproduced with permission from reference 32

and then into the visible vessel or over and around the bleeding area up to a total of 10 to $15 \mathrm{~mL}$ ) with or without added thrombin or $1 \%$ polidocanol (13). Initial hemostasis was achieved in 111 of 119 actively bleeding patients $(93 \%)$. Permanent hemostasis was defined as cessation of bleeding and absence of recurrence during hospitalization. Rebleeding occurred in 75 of the 341 patients $(22 \%)$, at a mean internal of $53 \mathrm{~h}$. A second emergency injection was attempted in 36 therapeutic failures, with hemostasis in $55 \%$. Surgery was required in 52 of the 341 patients $(15 \%)$ and overall mortality rate was $4.9 \%$. The major complications from injection therapy were few, and included two persons with perforations and two with aspiration pneumonia $(1.2 \%)$. As reported by others $(14-16)$, therapeutic failure was more frequent in patients with ulcers at the posterior wall of the duodenal bulb, close to the gastroduodenal artery. Thus, endoscopy has gone from being challenged as having any benefit for the patient with GIB to being the management of choice.

\section{ANTIFIBRINOLYTIC AGENTS}

The antifibrinolytic drug tranexamic acid was first studied in a randomized clinical trial for GIB 20 years ago. Henry and O'Connell (17) have performed a meta-analysis of six randomized double-blind placebo controlled trials of fibrinolytic inhibitors in 1267 patients with GIB from Britain, Sweden and Australia. In five of the six trials there was a high proportion of older persons. The prevalence of bleeding sites ranged from 43 to $88 \%$ peptic ulcers and 4 to $23 \%$ gastric erosions. Tranexamic acid 3 to $6 \mathrm{~g} /$ day was given in four trials and 4.5 to $12 \mathrm{~g} /$ day for a further two to seven days in two trials. Treatment with tranexamic acid was associated with a 20 to $30 \%$ reduction in the rate of rebleeding, a 30 to $40 \%$ reduction in the need for surgery and a $40 \%$ reduction in mortality. This beneficial effect - reduction in complications - was supported, for example, by a large single centre study from Notting. ham (18) of 775 patients presenting with hematemesis or melena or both. In those treated, $1 \mathrm{~g}$ tranexamic acid was given intravenously q6h for $48 \mathrm{~h}$ and then $1 \mathrm{~g}$ by mouth q6h, or treatment was intravenous cimetidine $400 \mathrm{mg}$ q6h for $48 \mathrm{~h}$, followed by $400 \mathrm{mg}$ by mouth q6h, compared with placebo. Mortality was reduced in patients receiving tranexamic acid $(6.3 \%$, $\mathrm{P}=0.0092$ versus placebo) or cimetidine $(7.7 \%, \mathrm{P}=0.045)$, compared with placebo $(13.5 \%)$. These differences persisted for tranexamic acid but not for cimetidine when excluding patients withdrawn from the study. Interestingly, treatment with tranexamic acid was not associated with any decrease in the rate of bleeding or the need for operation.

Unfortunately, the use of tranexamic acid is complicated by an increased incidence of thrombophlebitis 


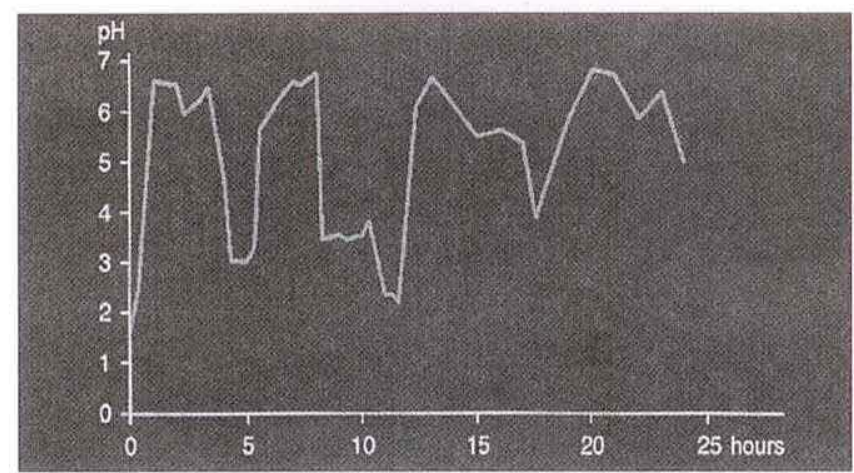

Figure 2A) Median $\mathrm{pH}$ in gastric juice after ranitidine bolus doses $50 \mathrm{mg} q 6 \mathrm{~h}(\mathrm{n}=9)$. Reproduced with permission from reference 41

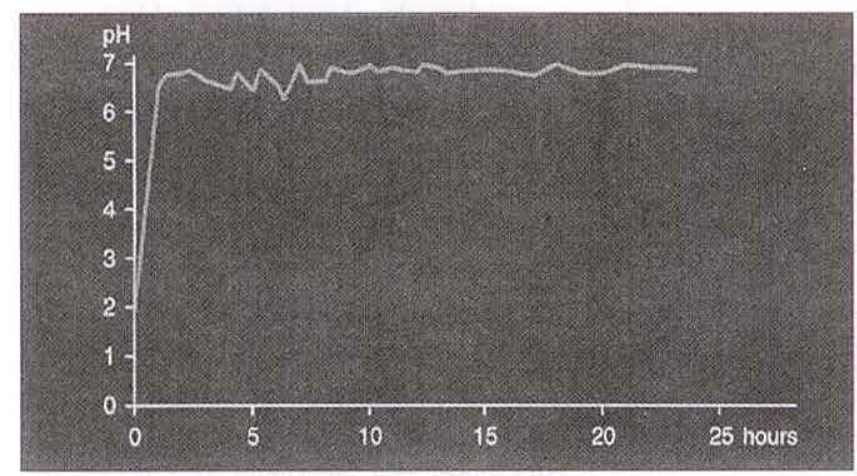

Figure 3A) Median pH in gastric juice after omeprazole continuous infusion $(80 \mathrm{mg}+8 \mathrm{mg} / \mathrm{h})(\mathrm{n}=9)$. Reproduced with permission from reference 41

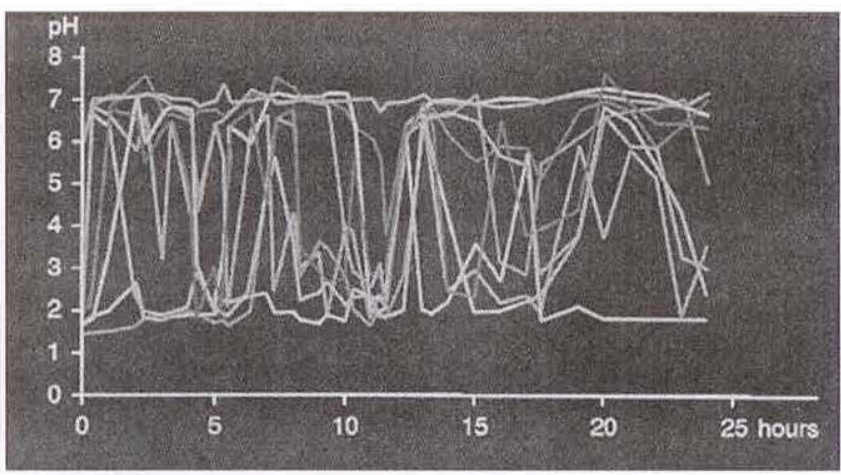

Figure 2B) Individual curves for $\mathrm{pH}$ in gastric juice after ranitidine bolus doses $50 \mathrm{mg} q 6 \mathrm{~h}(\mathrm{n}=9)$. Reproduced with permission from reference 41

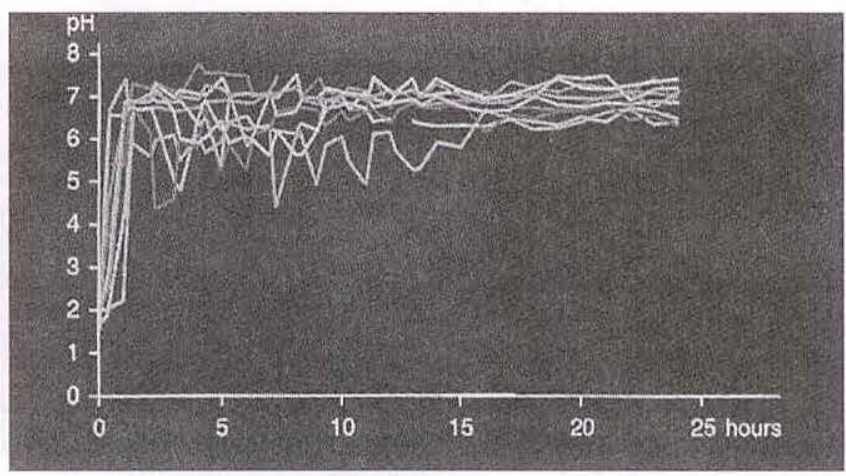

Figure 3B) Individual curves for $\mathrm{pH}$ in gastric juice after omeprazole continuous infusion ( $80 \mathrm{mg}$ bolus $+8 \mathrm{mg} / \mathrm{h})(n=9)$. Reproduced with permission from reference 41
(19). Despite this, it remains unclear why this form of therapy has not gained wider acceptance. The potential mechanism of benefit from this therapeutic agent is also uncertain.

\section{SOMATOSTATIN AND OCTREOTIDE}

Agents reducing splanchnic bloodflow have been studied in the treatment of patients presenting with hematemesis and melena. The hormone somatostatin reduces gastric acid secretion (20), pepsin (21) and gastrin secretion (22), and in noncirrhotics it reduces splanchnic bloodflow (23). A large double-blind controlled single centre study was performed in 630 unselected patients admitted to the Nottingham hospitals with hematemesis and melena (24). Placebo or somatostatin $250 \mu \mathrm{g}$ was given in an initial intravenous bolus followed by a $72 \mathrm{~h}$ intravenous saline infusion providing $250 \mu \mathrm{g}$ of somatostatin or placebo hourly. No difference was noted between somatostatin versus placebo in terms of rebleeding - 70 of $315(22 \%)$ with somatostatin versus 89 of 315 $(28 \%)$ with placebo - or operation rates - 35 of $315(11 \%)$ with somatostatin versus 25 of $315(8 \%)$ with placebo. None of these differences was statistically significant. However, it should be noted that 'all comers' were accepted and it could be argued that the inclusion criteria should be limited to those groups of patients in whom a low placebo-response rate can be expected to allow the trial drug a chance to show its potential efficacy.

In the study of somatostatin performed by Langman and colleagues (25), a generous dose of somatostatin was used, yet the study was negative. The somatostatin was given by infusion after a loading dose, so that the short half-life of about 3 mins is not a consideration. The somatostatin analogue octreotide (SMS 201-995, Sandoz, Basel, Switzerland) has a half-life of about 100 mins. In a second study, patients were included with GIB from bleeding gastric or duodenal ulcers requiring blood transfusion or plasma expanders. Christiansen et al (26) conducted a controlled 23 multicentre study in Denmark and Germany, with 123 patients on placebo and 115 on octreotide. There was no difference in the rates of stopping bleeding and preventing rebleeding between placebo (70.6\%) and octreotide $(69.6 \%)$, nor any difference between the two groups in surgery rates, blood transfusion requirements and time required before bleeding stopped.

Vasopressin has been used to treat patients with nonvariceal upper GIB, but there may be serious complications in those with cardiovascular or renal disease, and efficacy is marginal (2729).

\section{HISTAMINE $\mathrm{H}_{2}$ ANTAGONISTS}

Until September 1985 there were 27 reported randomized controlled clinical trials including about 2500 patients treated with histamine $\mathrm{H}_{2}$ antagonists, with no single study sufficiently large to stand alone and to provide clear-cut 


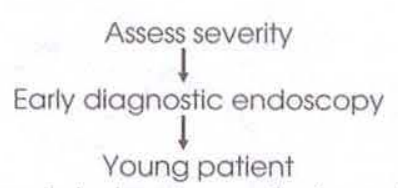

No associated major medical conditions

No systolic hypotension

No postural changes

Hemoglobin $>10$

No visible vessel, active bleeding or recent stigmata of bleeding

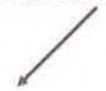

No hospitalization

-begin therapy of causative lesion, eg.

acid lowering therapy for peptic ulcer -transfuse for hemoglobin $<10$ or postural drop

-Helicobacter pylori eradication

therapy for duodenal

ulcer/gastroduodenal ulcer

$-\mathrm{H}_{2}$ receptor, eg.

famotidine $40 \mathrm{mg}$ intravenously.

followed by infusion for two days, then oral therapy for one month

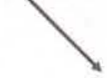

Hospitalization for severe disease -therapeutic endoscopy

-meticulous control of intragastric acid

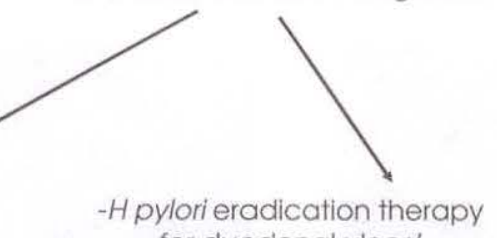

for duodenal ulcer/

gastroduodenal ulcer

-omeprazole intravenous bolus plus

infusion for two days, followed by oral therapy for one month

Figure 4) Suggested algorithm for patients with upper gastrointestinal bleeding

evidence of efficacy. In the absence of definitive studies, meta-analysis (which reviews critically the available clinical trials) assesses the homogeneity of any treatment such as $\mathrm{H}_{2}$ antagonists and pools the data to obtain an overall measure of benefit. The rates of persistent or recurrent bleeding was examined in 25 studies, the need for surgery in 22 studies or death in 24 studies (30). The proportion of patients in whom bleeding was judged to have been persistent or recurrent ranged from 10 to $45 \%$. Continued bleeding occurred somewhat less frequently in the treated patients than in the controls in 14 of the 24 studies. A statistically significant result $(\mathrm{P}<0.05)$ was noted in only one study (31). The odds ratio comparing the treated with the control groups was 0.89 , which was not a statistically significant beneficial effect. The need for surgery ranged from 0 to $35 \%$ in 22 studies, and there was a typical odds ratio of 0.78 in the patients treated with cimetidine or ranitidine. This is a statistically significant reduction, suggesting that treatment with $\mathrm{H}_{2}$ receptor antagonists reduces the operation rate by about $22 \%$. Fortunately the number of deaths in the trials was low and the combined mortality results from all studies indicate an odds rate of 0.70 , suggesting that treatment reduces mortality by about $30 \%(\mathrm{P}=0.02)$. For patients with bleeding from gastric ulcers, the combined data suggest that treatment significantly reduced these three major complications, whereas no differences were noted for patients with duodenal ulcers. It is therefore important to reconsider the routine use of systemic $\mathrm{H}_{2}$ receptor antagonists in all patients who present with GIB.

\section{PROTON PUMP INHIBITORS}

A single centre, double-blind placebo controlled study of 1147 unselected patients presenting with upper GIB to the Nottingham hospitals over a 42 -month interval was performed to compare placebo with $80 \mathrm{mg}$ omeprazole given intravenously immediately after admission to hospital and before endoscopic confirmation of bleeding or its site. The loading dose of omeprazole was followed by three doses of omeprazole $40 \mathrm{mg}$ intravenously by bolus at eight hourly intervals, then $40 \mathrm{mg}$ orally at $12 \mathrm{~h}$ intervals. Treatment was started within $12 \mathrm{~h}$ of admission and given for four days or until surgery, discharge or death. No significant differences were found between the placebo and omeprazole groups for rates of transfusion (301 of 569 [53\%] for placebo versus 289 of 578 [52\%] for omeprazole), rebleeding (100 [18\%] versus $85[15 \%])$, operation $(63[11 \%]$ versus $62[11 \%])$ and death (30 [5.3\%] versus $40[6.9 \%])$. The only difference was a significant reduction in endoscopic signs of bleeding in patients treated with omeprazole compared with those treated with placebo $(236[45 \%]$ for placebo versus $176[33 \%]$ for omeprazole, $\mathrm{P}<0.0001)$. Despite early reductions in signs of bleeding with omeprazole, mortality was not reduced. Logistic regression was used to analyze the combined effects of age, initial systolic blood pressure and bleeding site; for rates of rebleeding (overt hemorrhage), operation and death, increasing age and low initial systolic blood pressure were the strongest and most significant prognostic factors, and the presence of a gastric or duodenal ulcer was a significant factor for rebleeding and operation but not for death. No stratification was done for site or initial activity of bleeding lesions.

In contrast to this negative placebocontrolled study with 'all comers', Brunner and Chang (32) performed a smaller open randomized controlled trial (Figure 1) comparing intravenous therapy with ranitidine or omeprazole (omeprazole by bolus, $80 \mathrm{mg}$ initially followed by $40 \mathrm{mg}$ every $12 \mathrm{~h}$ for five days versus ranitidine $50 \mathrm{mg}$ followed by continuous infusion of $400 \mathrm{mg}$ ranitidine per day). Patients were critically ill with actively bleeding peptic ulceration. Successful treatment was proven by follow-up endoscopy on day 6 , unless there was earlier treatment failure. Of 20 patients in the ranitidine group, 17 were treatment failures with more than $2.5 \mathrm{~L}$ of blood necessary to maintain a hemoglobin level above $10 \mathrm{~g} / \mathrm{L}$ (Figure 1). Bleeding could be controlled sub. sequently in 13 of 17 patients after changing to omeprazole ( $76 \%$ ), and 16 of 19 patients started on omeprazole were successfully treated $(84 \%)$.

This open study success has been 
accompanied by a number of brief reports of the beneficial use of omeprazole to control hemorrhage from acute hemorrhagic gastritis (33), in five critically ill patients with life-threatening nonvariceal upper GIB who had failed to respond to conventional therapy (34) and in 11 older patients not responding to ranitidine or somatostatin, with persistence of clinical or endoscopic signs of bleeding due to erosive gastritis or acute peptic ulcer (the hemoglobin concentration was not raised despite four units of blood) (35).

The positive results of the study of Bruner and Chang (32) may have been due to the inclusion of patients with bleeding (36). The presence of active arterial bleeding at emergency endoscopy is associated with further hemorrhage in $95 \%$ of cases (4), while a nonbleeding visible vessel on the ulcer floor results in a rebleeding rate of 33 to $55 \%$. Stigmata of bleeding also provides a target to which endoscopic therapy must be addressed to obliterate the underlying artery $(14,37)$.

What is the rationale for using acid lowering therapy to treat patients with GIB? Humoral- and thrombocyte-induced hemostasis only occurs at $\mathrm{pH}$ values above 6.0 (38). Thrombocyte

\section{REFERENCES}

1. Thomson ABR, Walz L, Sutherland K. Total quality management at the Walter C Mackenzie Health Sciences Centre. Can J Gastroenterol 1994:8:11-4.

2. Allan RN. History epidemiology and mortality. In: Dykes PW, Keighley MRB, eds. Gastrointestinal Hemorrhage. Bristol: Wright PSG, 1981:3-20.

3. Allan R, Dykes PW. A study of the factors influencing mortality rates for gastrointestinal hemorrhage. Q J Med 1976;45:533-50.

4. Johnson JH. Endoscopic risk factors for bleeding peptic ulcer. Gastrointest Endosc 1990;36:S16-20.

5. Henry DA, Whyte I. Endoscopic coagulation for gastrointestinal bleeding. N Engl J Med 1988;318:185-7.

6. Sacks HS, Chalmers TC, Blum AL, Berrier J, Pagano D. Endoscopic hemostasis. An effective therapy for bleeding peptic ulcers. JAMA 1990;264:494-9.

7. Proceedings of the Consensus aggregation and clot formation are inhibited in the presence of even small amounts of acid, and newly formed clots are subject to rapid digestion by gastric juice at $\mathrm{pH}$ values below 5.0 (39). Pepsin further enhances platelet disaggregation. This argues for meticulous intragastric $\mathrm{pH}$ control in patients with upper gastrointestinal bleeding.

The various therapeutic regimens used in these studies include $\mathrm{H}_{2}$ receptor antagonists given by bolus, infusion or bolus plus infusion, and omeprazole given by bolus. The extent of acid control $(\mathrm{pH}$ greater than 5.0$)$ is better with cimetidine by infusion versus by bolus (40) and a loading dose of famotidine achieves superior acid control when given before infusion, compared with infusion alone (unpublished data). A loading dose of ranitidine does not add to the acid inhibiting effect of an infusion or ranitidine (unpublished data). The infusion of ranitidine results in considerable diurnal rhythm of intragastric values of $\mathrm{pH}$, with great variation between subjects (Figure 2). An intravenous bolus of omeprazole followed by infusion of proton pump inhibitor maintains the median intragastric $\mathrm{pH}$ consistently above 6 with little fluctuation and nontachyphylaxis (41,

Conference. Therapeutic endoscopy and bleeding ulcers: NIH

Consensus Conference. JAMA 1989;262:1369-72.

8. Rutgeerts P, Vantrapen G, Broeckaert L, Coremans G, Janssens J, Hiele M. Comparison of endoscopic polidocanol injection and YAG laser therapy for bleeding peptic ulcers. Lancet 1989;i:1164-7.

9. Laine L. Multipolar electrocoagulation versus injection therapy in treatment of bleeding peptic ulcers. A prospective randomized trial. Gastroenterology 1990;99:1303-6.

10. Lin HL, Tsai YT, Lee SD, et al. A prospective randomized trial of heat probe thermocoagulation versus pure alcohol injection in non-variceal peptic ulcer hemorrhage. Am ] Gastroenterol 1989;83:283-6.

11. Chung SCS, Leung JWC, Sung JY, Lo $\mathrm{KK}, \mathrm{Li} \mathrm{AKC}$. Injection or heat probe for bleeding ulcer. Gastroenterology 1991;100:33-7.

12. Balanzo J, Villaneuva C, Espinos JC, et al. Endoscopic injection therapy in bleeding peptic ulcers. Low mortality
42) (Figure 3). It now becomes appropriate to test this new and apparently ideal regimen in a clinical setting.

Three trials reported in abstract form have suggested that there may be a lower rate of rebleeding in patients with peptic lesions not due to nonsteroidal anti-inflammatory drugs, in whom anti-helicobacter therapy was initiated at the time of diagnosis of a bleeding peptic ulcer. Increasing evidence is accumulating to buttress the appropriateness of eradicating Helicobacter pylori to reduce the frequency of ulcer relapse, and this eradication therapy appears to be appropriate in patients presenting with a bleeding peptic lesion.

In summary, the patient who presents with acute upper GIB needs prompt clinical assessment and resuscitation (Figure 4). Early endoscopy is required for diagnosis therapy. Only patients with active bleeding or high risk of rebleeding, or medically endangered patients require admission to hospital. The role of routine use of systemic infusions of $\mathrm{H}_{2}$ receptor antagonists is not proven, and the promising role for meticulous control of intragastric $\mathrm{pH}$ using proton pump inhibitors needs to be established.

in a high risk population. Can ] Gastroenterol 1992;6:265-8.

13. Balanzo J, Villaneuva C, Sainz S, et al. Injection therapy of bleeding peptic ulcer. A prospective, randomized trial using adrenaline and thrombin. Endoscopy 1990;22:157-9.

14. Swain CP, Storey DW, Bown SG, et al. Nature of the bleeding vessel in recurrently bleeding gastric ulcers. Gastroenterology 1986;90:595-608.

15. Brullet E, Campo R, Bedos G, Barcons S, Gubern JM, Bordas JM. Site and size of bleeding peptic ulcer. Is there any relation to the efficacy of hemostatic sclerotherapy? Endoscopy 1991;23:73-5.

16. Steele RJC, Park KGM, Crofts TJ. Adrenaline injection for endoscopic homeostasis in non-variceal upper gastrointestinal hemorrhage. Br J Surg 1991;78:477-9.

17. Henry DA, O'Connell DL. Effects of fibrinolytic inhibitors on mortality from upper gastrointestinal hemorrhage. $\mathrm{Br}$ Med J 1989;298:1142-6. 
18. Barer D, Ogilvie A, Henry D, et al. Cimetidine and tranexamic acid in the treatment of acute uppergastrointestinal-tract bleeding. $\mathrm{N}$ Engl J Med 1983;308:1571-5.

19. Henry DA, O'Connell DL. Effects of fibrinolytic inhibitors on mortality from upper gastrointestinal haemorrhage. Br Med J 1989;298:1142-6.

20. Bloom SR, Mortimer $\mathrm{CH}$, Thorner $\mathrm{MO}$, et al. Inhibition of gastrin and gastric-acid secretion by growthhormone release inhibiting hormone. Lancet 1974;ii:1106-9.

21. Schrumpf E, Vatn MH, Hanssen KF, Myren J. A small dose of somatostatin inhibits the pentagastrin stimulated gastric secretion of acid, pepsin and intrinsic factor in man. Clin Endocrinol 1978;8:391-5.

22. Thomas WEG. Somatostatin the long lost antral chalone. Med Hypotheses 1980;6:919-27.

23. Varghese Z, Chan MK, Steele LV, Sweny P, Fernando ON, Moorhead JF. How to measure cyclosporin. Lancet $1984 ; \mathrm{i}: 1407-8$

24. Somerville KW, Gavies JG, Hawkey CJ, Henry DA, Hine KR, Landman MJS. Somatostatin in treatment of haematemesis and melena. Lancet $1985 ; \mathrm{i}: 130-2$.

25. Langman MJ. Upper gastrointesinal bleeding: The trials of virals. Gut 1985;26:217-20.

26. Christiansen J, Ottenjann R, Von Arx $\mathrm{F}$, and the Study Group. Placebo-controlled trial with the somatostatin analogue SMS 201-995 in peptic ulcer bleeding. Gastroenterology 1989;97:568-74.
27. Bar-Meir S, Conn HO. Spontaneous bacterial peritonitis induced by intraarterial vasopressin therapy. Gastroenterology 1976;70:418-21.

28. Conn HO, Ramby GR, Stoser EH, et al. Intraarterial vasopressin in the treatment of upper gastrointestinal hemorrhage: a prospective, controlled clinical trial. Gastroenterology 1975;68:211-21.

29. Millette B, Huet PM, Lavoie P, Viallet A. Portal and systemic effects of selective infusion of vasopressin into the superior mesenteric artery in cirrhotic patients. Gastroenterology 1975;69:6-12.

30. Collins R, Langman M. Treatment with histamine $\mathrm{H}_{2}$ antagonist in acute upper gastrointestinal hemorrhage. N Engl J Med 1985;313:660-6.

31. Londong W, Hasford J, Sander R, et al. Prevention of recurrent bleeding from gastroduodenal ulcers by combined application of cimetidine and pirenzepine: a double-blind randomized and multicentre trial. Excerpta Medica 1982;17:152-3.

32. Brunner G, Chang J. Intravenous therapy with high doses of ranitidine and omeprazole in critically ill patients with bleeding peptic ulcerations of the upper intestinal tract: an open randomized controlled trial. Digestion 1990;45:217-9.

33. Collier D St J, Crampton J, Everett WG. Acute haemorrhagic gastritis controlled by omeprazole. Lancet 1989;i:776. (Lett)

34. O'Leary MJ, Park GR. Intravenous omeprazole in upper gastrointestinal hemorrhage in critically ill patients. Digestion 1991;48:59-60. (Lett)
35. Gabriel SE, Jaakkimainen L, Bombardier C. Risk for serious gastrointestinal complications related to use of nonsteroidal antiinflammatory drugs. A meta-analysis. Ann Intern Med 1991;115:787-96.

36. Forrest JAH, Finlayson NDL, Shearman DJL. Endoscopy in gastrointestinal bleeding. Lancet 1974;ii:395-7.

37. Swain CP. Pathophysiology of bleeding lesions. Gastrointest Endosc 1990;36:S21-2.

38. Green FW, Kaplan MM, Curtis LE, Levine PH. Effect of acid and pepsin on blood coagulation and platelet aggregation. Gastroenterology 1978;74:38-43.

39. Berstad A. Antacids, pepsin inhibitors, and gastric cooling in the management of massive upper gastrointestinal hemorrhage. Scand J Gastroenterol 1987;22(Suppl 137):33-8.

40. Ostro MJ, Russell JA, Solden SJ, Mahon WA, Jeejeebhoy KN. Control of gastric $\mathrm{pH}$ with cimetidine: boluses versus primed infusions. Gastroenterology 1985;89:532-7.

41. Cederberg C, Thomson ABR, Kirdekis $\mathrm{P}$, Kristensson C. Effect of continuous intravenous infusion of omeprazole on 24-hour intragastric $\mathrm{pH}$ in fasting DU-patients: Comparison of repeated bolus doses of omeprazole or ranitidine. Gastroenterology 1992;102:A48.

42. Cederberg $\mathrm{C}$, Thomson ABR, Mahachai V, et al. Effect of intravenous and oral omeprazole on 24-hour intragastric acidity in duodenal ulcer patients. Gastroenterology 1992;103:913-8. 


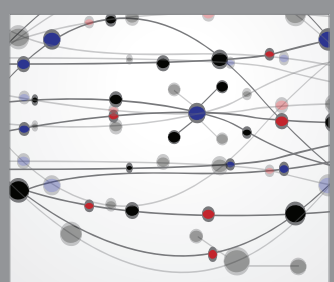

The Scientific World Journal
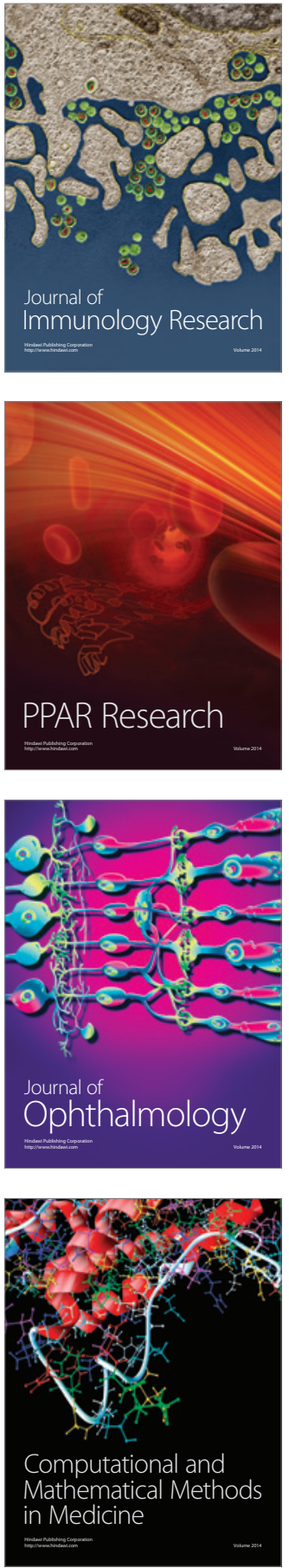

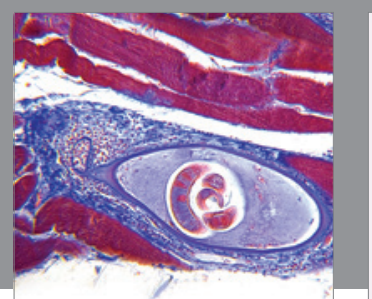

Gastroenterology Research and Practice

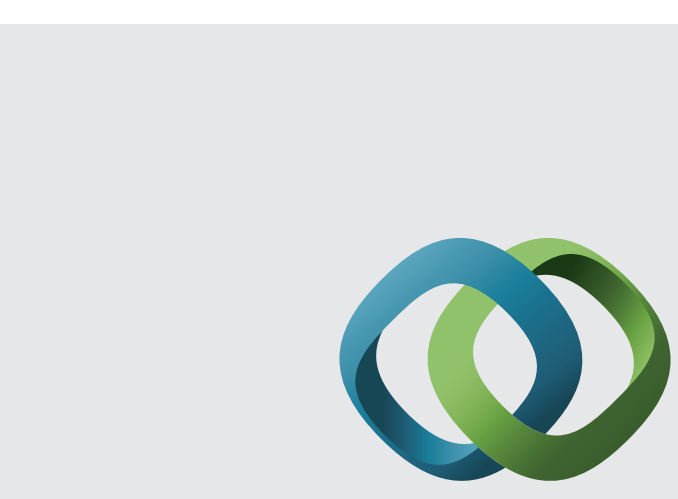

\section{Hindawi}

Submit your manuscripts at

http://www.hindawi.com
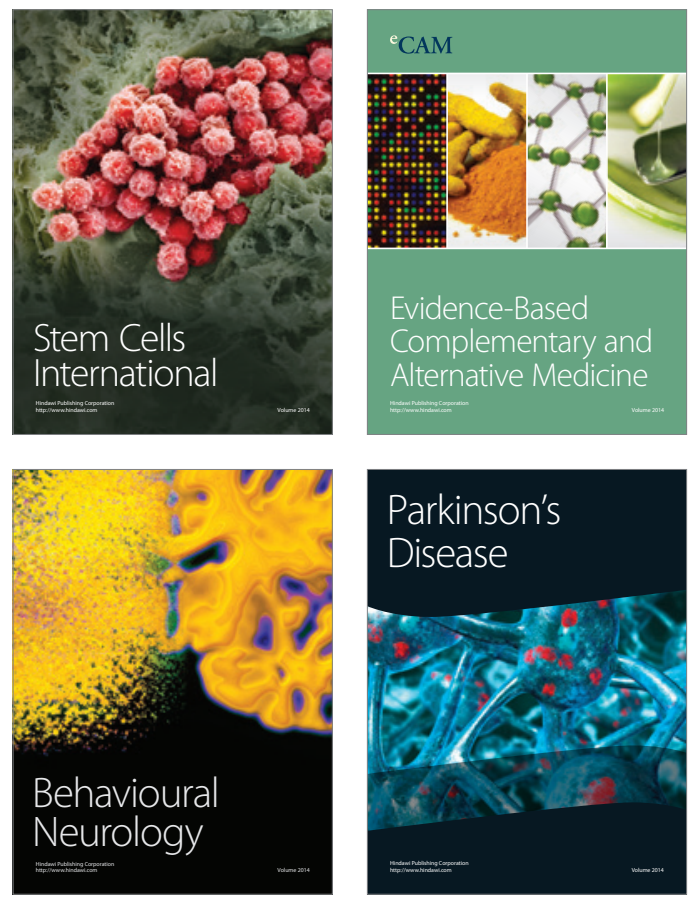
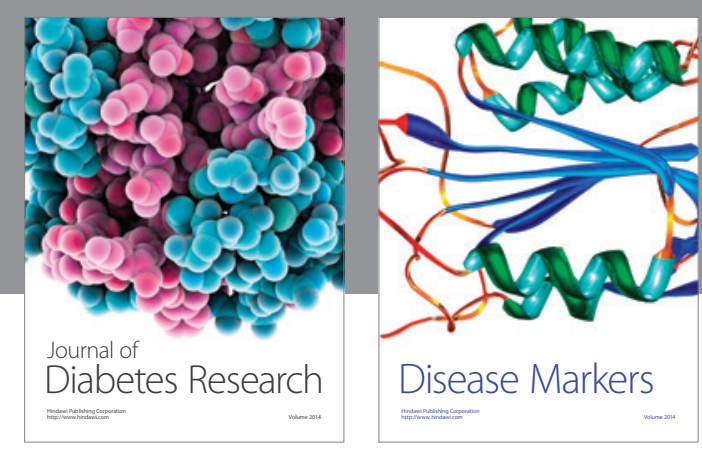

Disease Markers
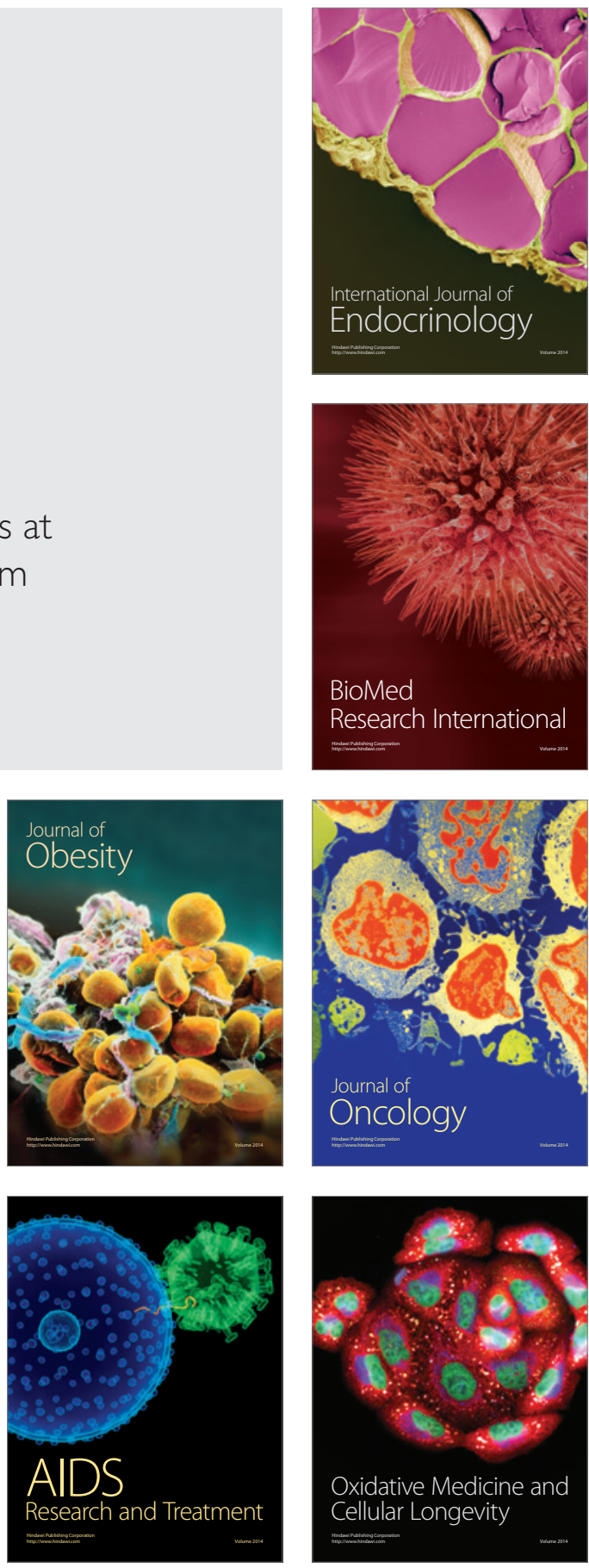